\title{
Integração de Tecnologia Educacional na USP
}

\author{
Educational technology integration at the University of São Paulo
}

\author{
Ewout ter Haar ${ }^{1}$ (D)
}

\begin{abstract}
RESUMO
Analisamos a integração de tecnologia educacional na Universidade de São Paulo, focando na adoção e uso de ambientes virtuais de aprendizagem (AVA), traçando seu desenvolvimento e manutenção nas últimas duas décadas. É proposto um arcabouço analítico para situar os principais marcos do uso das tecnologias online pela USP e que busca navegar entre os extremos de determinismo tecnológico e um instrumentalismo ingênuo. As formas de uso do principal AVA da USP, a plataforma e-Disciplinas, são exploradas por meio de indicadores de adoção e tipos de uso. A pandemia de 2020 acelerou repentinamente uma tendência existente de maior adoção e usos mais complexos do sistema.
\end{abstract}

Palavras-chave: Tecnologia educacional; Integração de tecnologia; Ensino superior; Ambiente virtual de aprendizagem; Covid-19

\begin{abstract}
We analyze educational technology integration at the University of São Paulo (USP), focussing on the adoption and use of Learning Management Systems (LMS), tracing their implementation and maintenance in the last two decades. An analytical framework is proposed that situates the main milestones of online technology use at USP and that aims to navigate between the extremes of technological determinism and naive instrumentalism. The use of the main LMS of USP, the e-Disciplinas platform, is explored by adoption and other indicators. We show how the 2020 pandemic accelerated an already existing tendency towards higher intensity and more complex forms of use of the platform.
\end{abstract}

Keywords: Educational technology; Technology, integration; Higher, education; Learning, management, systems; Covid-19

\section{MENSAGENS PRINCIPAIS:}

- A integração de tecnologia educacional na Universidade de São Paulo (USP) vem acontecendo nos últimos 15 anos, e este artigo apresenta esta história focando na adoção e uso dos chamados ambientes virtuais de aprendizagem (AVA);

- A história dos AVAs é interpretada com ajuda de um arcabouço teórico que postula a necessidade de três níveis de análise: a adoção das tecnologias, as suas formas de uso e suas consequências político-pedagógicas;
- $\quad$ A USP enfrentou o "ensino remoto emergencial" da pandemia de 2020 a partir de uma situação relativamente favorável, por ter muitos docentes, discentes e servidores já com bastante experiência no uso de tecnologias do tipo AVA;

- Instituições de ensino como a USP precisam manter sua autonomia e capacidade técnica de organizar seus próprios ambientes de aprendizagem online, analisando criticamente as tecnologias educacionais e fazendo valer seus próprios valores político-pedagógicos, para não necessariamente depender de plataformas de terceiros.

\footnotetext{
${ }^{1}$ Prof. Doutor do Instituto de Física da Universidade de São Paulo
} 


\section{INTRODUÇÃO}

Quando, em março de 2020, ficou claro que atividades presenciais na USP teriam que ser suspensas temporariamente, em decorrência da pandemia do novo coronavírus (SARS-CoV-2), muitos docentes conseguiram, em pouco tempo, configurar, senão um curso de ensino à distância $(E a D)$, pelo menos algum tipo de ensino remoto emergencial (ERE). Esta transição rápida para o ensino online foi facilitada pela existência de infraestrutura de tecnologia educacional na Universidade de São Paulo (USP), fruto de uma década de desenvolvimento e manutenção. Para embasar esta afirmação mostramos, na Figura 1, que logo após o início da pandemia o uso do principal Ambiente Virtual de Aprendizagem (AVA) para hospedar ambientes educacionais online da USP, a plataforma "e-Disciplinas", triplicou quando comparado a igual período no ano anterior. No entanto, o número de participantes ativos aumentou somente $30 \%$, mostrando que esta tecnologia já era conhecida e vinha sendo usada, embora em nível menor, por grande parte dos docentes e discentes da USP.

Como a USP chegou naquele momento, no início da pandemia, em uma condição bastante adequada e favorável para enfrentar a emergência global em 2020?

Desde o início dos anos 2000 estava claro que as tecnologias de informação e comunicação seriam integradas aos processos educacionais do ensino superior. Mas como estes processos seriam mediados e modificados pelas tecnologias online e da internet seria objeto de constante debate e contestação ao longo dos anos. Neste artigo, descrevemos a história da integração de tecnologia educacional na USP nos últimos 15 anos, focando essencialmente nos AVAs. É uma história orientada na direção do ensino híbrido, da integração de tecnologia a processos tradicionais e presenciais de educação. Como veremos, dois projetos de EaD tiveram papel importante na adoção das tecnologias online na USP e na difusão de conhecimento sobre elas.

Porém, qualquer história deve ser analisada criticamente para ser interpretada. Para ajudar com a análise, um arcabouço teórico é proposto, trazendo alguns autores da história e filosofia da tecnologia. Em seguida, relatamos alguns marcos do uso das tecnologias online pela USP e como foram incorporados nos processos de ensino-aprendizagem. Finalizamos com breves considerações sobre as consequências político-pedagógicas desta transformação.

$80 \mathrm{mil}$

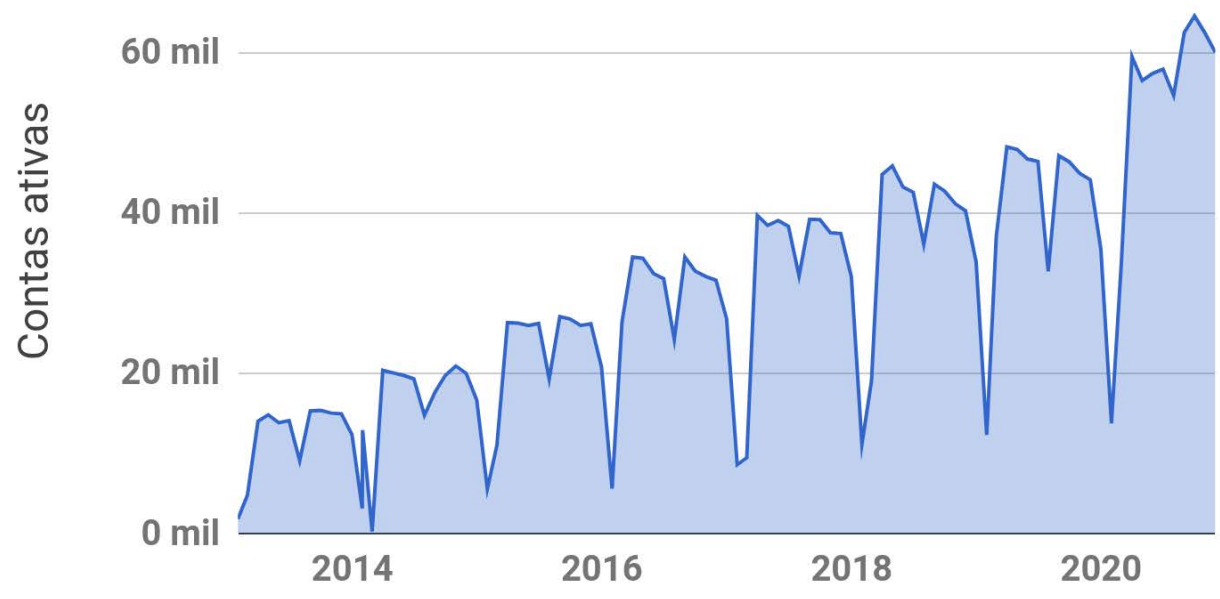




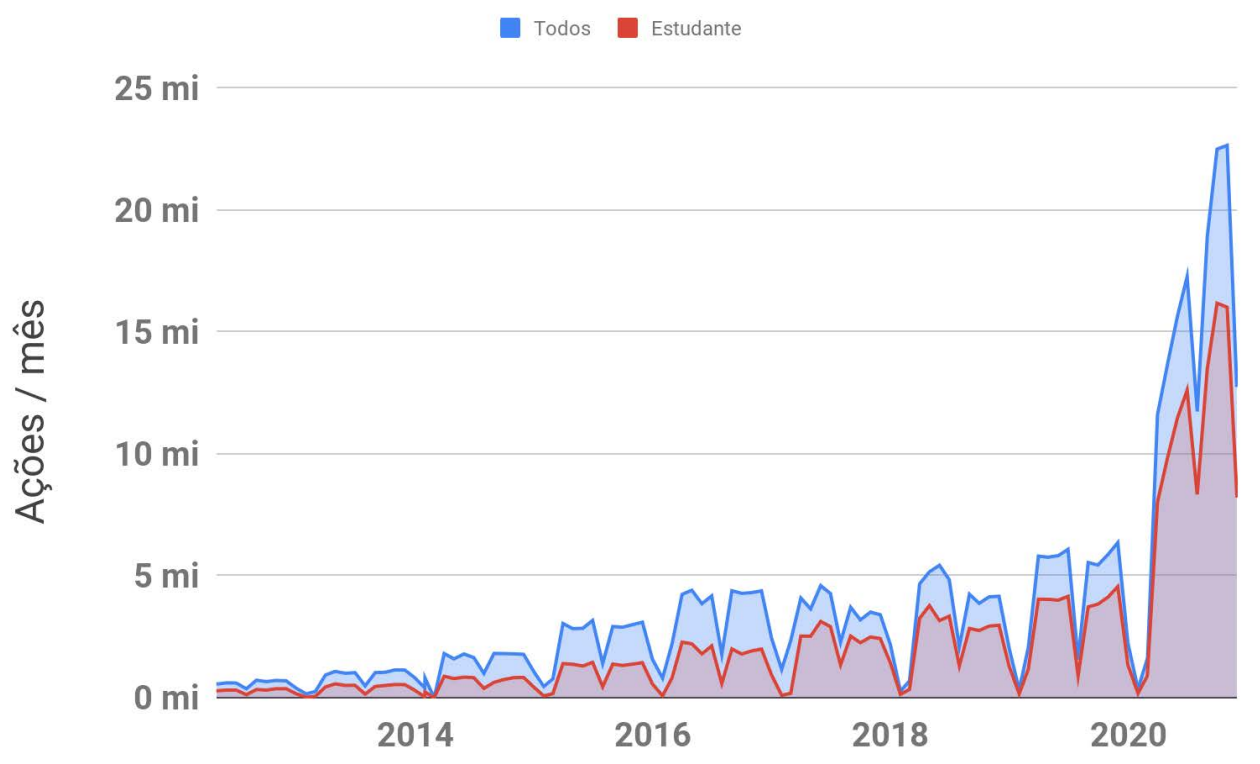

Figura 1:Atividade no e-Disciplinas, o principal AVA da USP. Acima: contas ativas no mês. Abaixo: número de interações com o sistema por mês.

\section{COMO ANALISAR A INTEGRAÇÃO DE TECNOLOGIA EDUCACIONAL}

Começamos com algumas considerações programáticas e metodológicas. Vamos fazer a análise das modificações nas práticas educacionais associadas a mudanças tecnológicas em três níveis. Primeiro, do ponto de vista do acesso às tecnologias e da sua adoção. Neste nível da análise a pergunta é, se a tecnologia é usada e como se deu o processo de adoção da mesma. Segundo, como a tecnologia é usada e como se adapta para se adequar aos fins pedagógicos dos usuários. Finalmente, não podemos entender a adoção e o uso de tecnologias educacionais sem levar em consideração suas consequências político-pedagógicas e como elas interferem e mudam a prática docente, incluindo as potencialidades de aumento de eficiência e enriquecimento dos processos educacionais, ou do outro lado o risco de precarização da docência.

No primeiro nível de análise são abordadas questões de acesso à tecnologia, a existência de infraestrutura necessária e consequências da desigualdade no acesso ${ }^{1}$.
Um arcabouço amplamente usado para estudar a adoção de inovações é o da "difusão de inovações" de Rogers². Nesta abordagem, determinadas inovações de sucesso mostram uma curva " $S$ " de adoção ao longo do tempo. Existem diferentes categorias de pessoas, dos adeptos de primeira hora até retardatários, e a difusão da inovação se dá por processos de comunicação pelos quais as pessoas tomam conhecimento da inovação. O arcabouço de Rogers é interessante em sua ênfase nos mecanismos de comunicação e persuasão que convencem pessoas a adotarem as inovações. Existem estudos que reportam que persuasão e contato com colegas e pares mais próximos são, de fato, um dos fatores mais importantes na decisão de adotar tecnologias educacionais (num contexto de aprendizagem híbrida $)^{3,4}$. Mas há limitações inerentes ao uso de um arcabouço focado na adoção de inovações ou invenções. A primeira é o viés induzido pelo foco na inovação como algo necessariamente positivo e o pressuposto de que a inovação representa inevitavelmente progresso. Na verdade, pessoas na categoria laggards ou retardatários, a despeito da nomenclatura com suas conotações pe- 
jorativas, podem ter suas razões, perfeitamente racionais, para não adotarem uma nova tecnologia. A ideia de que as tecnologias são inevitáveis e sempre levam ao progresso pode ser chamada de determinismo tecnológico e também não correspondem à verdade.

Um entendimento mais rico da tecnologia e sua história é o do historiador David Edgerton, no seu livro Shock of the Old ${ }^{5}$. Neste livro, o autor faz uma análise de tecnologia-em-uso, mostrando como a inserção de tecnologias na sociedade é um processo mais complexo do que uma mera sequência de inovações adotadas passivamente pela sociedade. Mostra que tecnologias são inseridas nas práticas de pessoas e organizações de forma mais desordenada e situada do que uma simples sequência de adoção de novidades. Tecnologias são adaptadas para cada realidade, com grandes variações geográficas, contrariando uma narrativa simples de invenções feitas num determinado local (i.e. no Vale do Silício, na narrativa comum) que, então, se difundem pelo mundo. Tecnologias novas coexistem com as antigas, não as substituem.

Em ambientes educacionais as contradições do determinismo tecnológico são bem visíveis e uma consequência disto está muito bem expressa no título do livro de Larry Cuban, Oversold and underused - computers in the classroom ${ }^{6}$, ou seja, a tecnologia supervalorizada e mal aproveitada. Isto é visível em programas que impõem tecnologias educacionais sem criar primeiro as condições necessárias para que estas tecnologias se insiram organicamente na realidade institucional. Em ambientes educacionais contemporâneos o potencial das tecnologias educacionais somente tem chance de se expressar se estas forem inseridas de forma situada, consciente do contexto e com protagonismo dos atores locais.

Precisamos, portanto, de um segundo nível de análise, o das formas de uso e capacidade de adaptação à tecnologia. Em vez de focar a atenção unicamente em adoção, é preciso analisar como as tecnologias são usadas, em qual contexto, por quem e para qual finalidade. Desta forma tiramos a tecnologia em si do centro das atenções e começamos a estudá-la no contexto institucional e sistêmico, como ela se relaciona com agentes, que têm, por sua vez, moti- vações e objetivos. O enfoque em implantações de inovações, nesta outra abordagem, dá lugar a uma análise de como elas são sustentadas, como crescem, se enraízam e se adaptam dentro de cada instituição.

Mas nesta análise de como as tecnologias educacionais são usadas é preciso não cair na armadilha do instrumentalismo ingênuo, ou a ideia de que a tecnologia é neutra, uma mera ferramenta. A crítica de que tecnologias não são neutras estão nos escritos de acadêmicos desde Lewis Mumford e Heidegger, nos anos 1930 e 1940, até Langdon Winner ${ }^{7}$. Muito citado também é o enunciado do historiador de tecnologia Melvin Kranzberg ${ }^{8}$ : "a tecnologia não é ruim ou boa, nem é neutra". O discurso de que uma tecnologia é uma mera ferramenta neutra porque pode ser usada de diferentes maneiras, perde força na medida em que consideramos tecnologias mais complexas tais como armas nucleares (o exemplo de Langdon Winner) ou a internet e suas aplicações (como vivido no momento atual em todo o planeta). Além disso, as decisões sobre quais tecnologias são desenvolvidas ou em quais serão investidos mais recursos obviamente dependem de condições políticas e sociais em cada localidade e contexto. Desta forma, as tecnologias não somente exercem forte influência sobre a sociedade, mas também sobre a política e fatores sociais, por sua vez, exercem influência sobre as tecnologias na sua função e sua essência.

Desta forma, a neutralidade das "plataformas" de tecnologia educacional como AVAs deve ser questionada. Algumas atividades são facilitadas, outras não. É simples disponibilizar conteúdo, pode ser mais complexo criar atividades dialógicas. É simples criar questões de múltipla escolha, enquanto dá mais trabalho criar avaliações com feedback aos estudantes. Do ponto de vista de políticas educacionais, o sistema pode facilitar salas de aula massificadas (por conta da automatização), mas pode não incentivar processos colaborativos entre grupos pequenos. Assim, a ferramenta revela-se não-neutra com respeito a metodologias educacionais e tampouco com respeito a políticas educacionais. Estes exemplos mostram que é preciso engajar-se ativamente com as possibilidades e dificuldades destas tecnologias. A palavra inglesa affordance ${ }^{9}$ expres- 
sa a ideia de que o que uma tecnologia permite deve ser avaliado em relação ao seu usuário e ao contexto em que foi inserida. Não faz sentido considerar as virtudes ou os vícios da tecnologia educacional isoladamente, sem considerar implementações concretas. Tecnologia educacional pode propiciar mais oportunidades de aprendizagem ou melhores condições de trabalho, mas isso vai depender de qual sistema (educacional e político) determinada tecnologia está inserida. Em resumo, é preciso navegar entre os extremos de um determinismo tecnológico e um instrumentalismo ingênuo.

\section{A TECNOLOGIA NO SEU CONTEXTO: ADOÇÃO DE AVAS NA USP}

A USP é uma das maiores universidades do Brasil, contando com 59 mil alunos matriculados em disciplinas da graduação e 23 mil alunos na pós-graduação no ano de 2020. A cada ano são oferecidas aproximadamente 10 mil disciplinas de graduação e 4.500 de pós-graduação, por cerca de 6.300 ministrantes. Como em outras universidades de ponta voltadas à pesquisa, docentes, departamentos e unidades têm muita autonomia nas escolhas de quais tecnologias educacionais usam para apoiar sua prática pedagógica.

Esta autonomia, porém, não quer dizer que os docentes não sejam restringidos pelo contexto institucional e tecnológico em que estão inseridos. As escolhas "se" e "como usar" tecnologias para criar ambientes de aprendizagem são influenciadas por vários fatores, incluindo a cultura departamental, incentivos institucionais, fatores pessoais como a familiaridade com as tecnologias, experiências passadas e fatores relacionados com a própria disponibilidade das mesmas.

Para muitos docentes, a primeira experiência com tecnologias educacionais mediadas pela internet se dá por meio de um AVA. Com o amadurecimento e a ampliação da oferta da internet no final dos anos 1990, foram consolidadas várias maneiras de usar essa infraestrutura para fins educacionais, como fóruns ou hospedagem de páginas Web, dentro de um único sistema. $O$ AVA nasceu como sistema corporativo com gestão centralizada ${ }^{10}$.
Inicialmente a implementação de AVAs na USP no início dos anos 2000 se deu desta forma centralizada, com o oferecimento de sistemas como Web Course Tools (WebCT) pelo órgão central de tecnologia da informação (TI) da USP. Este oferecimento foi descontinuado quando o software foi adquirido pela empresa Blackboard, levando a um grande aumento do custo da licença de uso. Esta experiência incentivou a busca por soluções internas. O sistema COL - Cursos Online ${ }^{11}$ era um sistema do tipo AVA desenvolvido por engenheiros de computação de escola politécnico da USP e foi usado por muitos anos, que foi substituído por outra iniciativa de engenheiros de computação, o projeto Tidia-AE ${ }^{12}$. Ambos os sistemas pretendiam oferecer um AVA institucional para a USP inteira. O Tidia-AE fazia parte do programa Tecnologia da Informação no Desenvolvimento da Internet Avançada financiado pela Fundação de Amparo à Pesquisa do Estado de São Paulo (FAPESP) entre 2004 e 2009, que visava o desenvolvimento de ferramentas de suporte e apoio ao ensino e aprendizagem e acabou adaptando o software aberto Sakai ${ }^{13}$.

Estas tentativas de disponibilizar um AVA institucional aconteceram num momento de "democratização" de aplicações da Web por meio da disponibilidade de um conjunto de softwares abertos usando as tecnologias LAMP (Linux, Apache, Mysql e PHP), o que viabilizou que indivíduos ou pequenos grupos de pesquisa oferecessem serviços da Web como Fóruns, Wikis e também AVAs, algo que antes era reservado a empresas ou instituições com muito mais recursos. Mesmo pesquisadores individuais ou pequenos grupos de pesquisa puderam oferecer serviços de tecnologia educacional e muitos departamentos ou unidades da USP começaram instalar e oferecer serviços como o do software livre Moodle ${ }^{14}$ que significa Modular Object-Oriented Dynamic Learning Environment. Outra alternativa desenvolvida na Unicamp foi o TelEduc ${ }^{15}$. Neste período alguns departamentos da Escola Politécnica e a Escola de Artes, Ciências e Humanidades orientaram o uso do Tidia-AE, mas outras, como a Faculdade de Economia e Administração forneceram um sistema próprio (o Erudito) e vários departamentos da Escola Politécnica, o Instituto de Matemática, a Faculdade de Odontologia e a Faculdade de Medicina, entre outros, implementaram suas próprias instalações do Moodle. 
É neste contexto de descentralização e experimentação com tecnologias da Web que o AVA e-Disciplinas surgiu, em 2009, como parte de um projeto chamado Stoa, que visava incorporar tecnologias de redes sociais em contextos de ensino superior. O projeto foi implementado com o software aberto Elgg (a partir de 2012 migrou para Noosfero) e forneceu um espaço na Web, com blog, espaço para arquivos, fóruns e perfil pessoal para todos os discentes, docentes e servidores da USP. O projeto ambicionava criar redes de colaboração e comunicação horizontais, desvinculados das hierarquias e divisões disciplinares tradicionais da academia.

Em retrospecto, o projeto Stoa sofreu de uma visão instrumentalista, que, como descrevemos acima, assume que só oferecer uma plataforma com determinada arquitetura do software seria suficiente para efetuar mudanças nos usuários, nas formas de comunicação ou nas relações entre pessoas. O projeto teve uma relação inquieta com dirigentes e sofreu com a falta de interesse dos docentes da instituição. No entanto, quando em 2009, foi acrescentado ao projeto o AVA "Moodle do Stoa" percebeu-se uma aceitação imediata por parte destes atores. O número de usuários ativos e o uso do Moodle do Stoa, mais tarde renomeado para e-Disciplinas, cresceu $30-50 \%$ por ano entre 2010 e 2020, inicialmente entre os docentes das Unidades da USP que não podiam contar com um AVA próprio, o que resultou em um processo gradual de centralização, substituindo cada vez mais os múltiplos AVAs existentes em cada unidade.

Por volta de 2010 houve dois choques externos que influenciaram em muito a integração de tecnologia educacional na USP na década seguinte. O programa REDEFOR (Rede São Paulo de Formação Docente) era uma parceria da Secretaria Estadual de Educação de São Paulo com as três universidades estaduais, oferecendo cursos de especialização (18 meses de duração) na modalidade à distância. Com dois oferecimentos, entre 2010 e 2012, esta parceria possibilitou e incentivou, por meio dos seus recursos financeiros, um grande investimento na criação de competência em EaD. Foram formadas equipes de design instrucional, web designers, tutores para acompanhamento online e equipes técnicas que operacionalizaram o AVA (baseado no Moodle) para estruturar os cursos que seriam oferecidos na Universidade.

A experiência destas equipes foi utilizada no primeiro curso de graduação na modalidade semipresencial da USP, a licenciatura em Ciências. Em convênio com o Programa UNIVESP, vinculado à extinta Secretaria de Ensino Superior do Estado de São Paulo e em 2012 transformado em Universidade ${ }^{16}$, o curso admitiu cinco turmas de 360 alunos e foram montados sete polos, na capital e no interior do Estado, em vários campi da USP. Novamente, foi montada uma grande estrutura com os profissionais necessários para oferecer um curso de EaD de qualidade.

Apesar da duração limitada destas duas iniciativas de EaD na USP, sua existência teve efeitos importantes para a viabilidade do AVA eDisciplinas. Primeiro porque permitiu dentro da USP a criação de capacidade técnica para operacionalizar o AVA Moodle em grande escala. Desenvolveu-se também um processo de manutenção e atualização do software que foi aproveitado para o e-Disciplinas (e mais tarde para - Moodle Extensão), para viabilizando atender a crescente demanda por docentes de cursos regulares de graduação, pós-graduação e os projetos de extensão com milhares de participantes.

Na USP não há o equivalente a um "Center for Teaching and Learning" (CTL) que, em universidades nos EUA e na Europa, apoiam docentes na integração de tecnologias educacionais e, muitas vezes, providenciam de forma centralizada tecnologias educacionais como AVAs. Durante a existência da Redefor e a Licenciatura em Ciências, as equipes destes projetos podiam parcialmente atender algumas das funções típicas de um CTL, o que também ajudou na aceitação do e-Disciplinas.

No início de 2020, quando todos foram assolados pela pandemia da Covid-19, um docente da USP já podia escolher entre três AVAs mantidos oficialmente pela instituição: um Moodle (com nome e-Disciplinas), um Sakai (com nome Tidia-AE) e Google Classroom (via G-Suíte). Há também os sistemas dos departamentos, os mais notáveis sendo os Moodles da Escola Politécnica (pelo menos quatro), o Moodle do IME (Instituto de Matemática e Estatística) e os AVAs da Facul- 
dade de Medicina. Finalmente, o docente também tem autonomia para usar outra plataforma fora da USP, mantida pela iniciativa privada.

Apesar do cenário inicial mais descentralizado, com o tempo houve uma tendência de con- solidação do modelo mais centralizado no Moodle. Em 2020, 70\% das matrículas em disciplinas de graduação contavam com um ambiente de apoio no e-Disciplinas da USP (Figura 2).

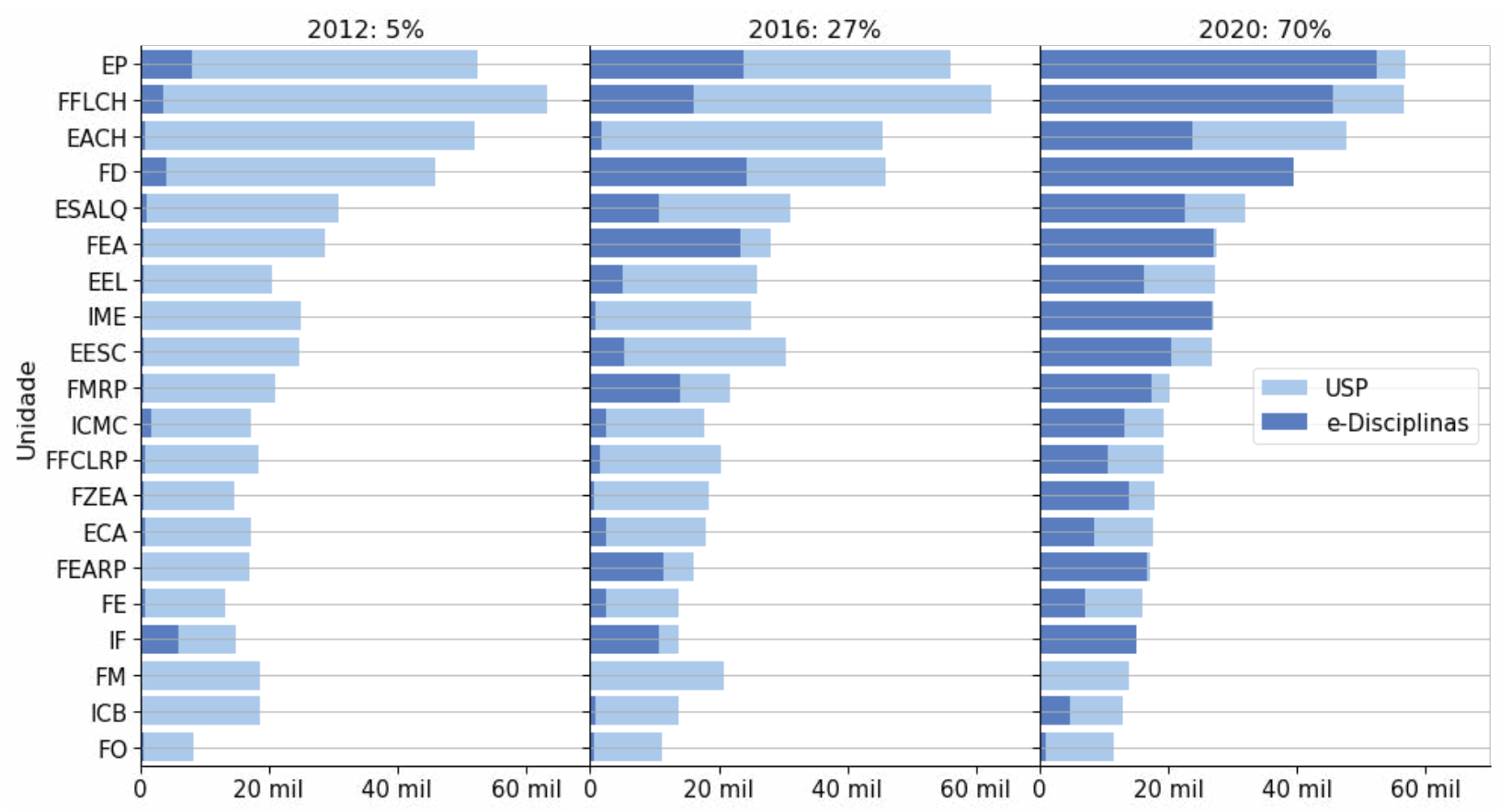

Figura 2: Evolução do número de matrículas em ambientes de apoio online no e-Disciplinas, em comparação com todas as matrículas da USP (Graduação).

A média total esconde a variação por unidade. Cada unidade tem a sua história particular que poderia explicar o padrão de adoção. Em 2016 a Faculdade de Economia e Administração (FEA) desistiu do seu AVA desenvolvido "em casa", e com apoio da diretoria da unidade adotou o Moodle da USP. A Faculdade de Medicina usa seu próprio Moodle e o Google Classroom. É possível supor algumas das razões que nos ajudam a explicar/ entender esta variação observada para além de observações informais. A literatura ${ }^{4}$ sugere fortemente que as interações com pares próximos são um dos determinantes mais fortes que motivam docentes individuais a experimentar e eventualmente integrar novas tecnologias na sua prática.
Estas interações entre colegas, porém, acontecem dentro de um contexto institucional. Observamos que, em unidades onde há um forte apoio técnico local, como na FEA ou a Faculdade de Medicina de Ribeirão Preto (FMRP) o efeito contágio é potencializado, resultando em uma adoção que se estende rapidamente pela unidade.

\section{TECNOLOGIAS: POTENCIALIDADES E VARIEDADES DE USO}

A adoção de tecnologias, por si só, tem valor educacional limitado. Para estudar o uso da tecnologia educacional além da mera adoção, é 
preciso qualificar métricas de quantidade e qualidade, assim como observar como os docentes fazem uso da plataforma. É notório entre especialistas em tecnologia educacional ${ }^{17}$ que o primeiro contato com tecnologias como AVAs resulta em usos simples, como o de um repositório de arquivos para distribuir recursos didáticos entre seus alunos, ou como forma de comunicação e envio de avisos administrativos. Podemos analisar como os docentes da USP estruturam seus ambientes de apoio online por meio do tipo de módulo do Moodle que usam. Um módulo é uma atividade do AVA como questionário, tarefa ou fórum, ou um tipo de material didático como arquivos ou vídeos.
Observamos que aproximadamente um quarto dos ambientes são "repositórios", ou seja, ambientes usados apenas para disponibilizar material didático e sem nenhuma atividade participativa (Figura 3). Há também indícios de que a maneira como os docentes estruturaram seus ambientes de apoio se modificou, pelo menos ligeiramente, entre 2012 e 2019, no sentido de usar mais módulos com finalidade de avaliação (as ferramentas "Questionário" e "Tarefa" no Moodle). O número médio por disciplina deste tipo de módulo aumentou quase duas vezes em 2012, e cerca de três a quatro vezes após 2015 .
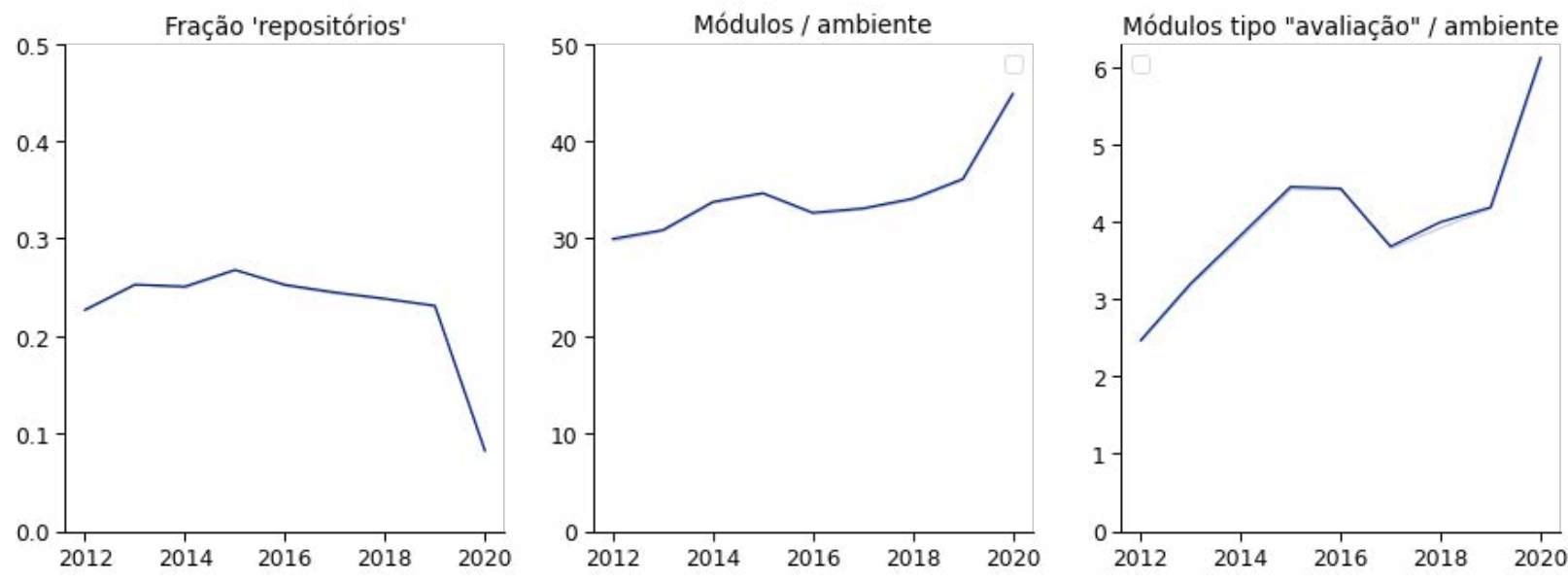

Figura 3: Como docentes da USP estruturam seus ambientes de apoio às suas disciplinas no AVA e-Disciplinas. Esquerda: fração dos ambientes somente com arquivos. Meio: número médio de módulos (recursos e atividades online) em cada ambiente. Direita: número médio de atividades avaliativas por ambiente (envio de arquivo ou questionários).

Obviamente, uma grande mudança ocorreu em 2020, quando a pandemia de COVID-19 forçou todos os docentes, não somente os já adeptos ao AVA, a migrar sua prática de ensino e avaliação para o ambiente online. Quem usava o e-Disciplinas somente para repositório, agora começou a usar mais recursos do sistema. O número de mó- dulos por ambiente aumentou e mais atividades de avaliação foram usadas. A Figura 4 mostra que não somente aumentou o número total de módulos usados em ambientes, como também aumentou a diversidade de módulos (de 3 para quase 5 tipos diferentes de módulos usados por ambiente, em média) 

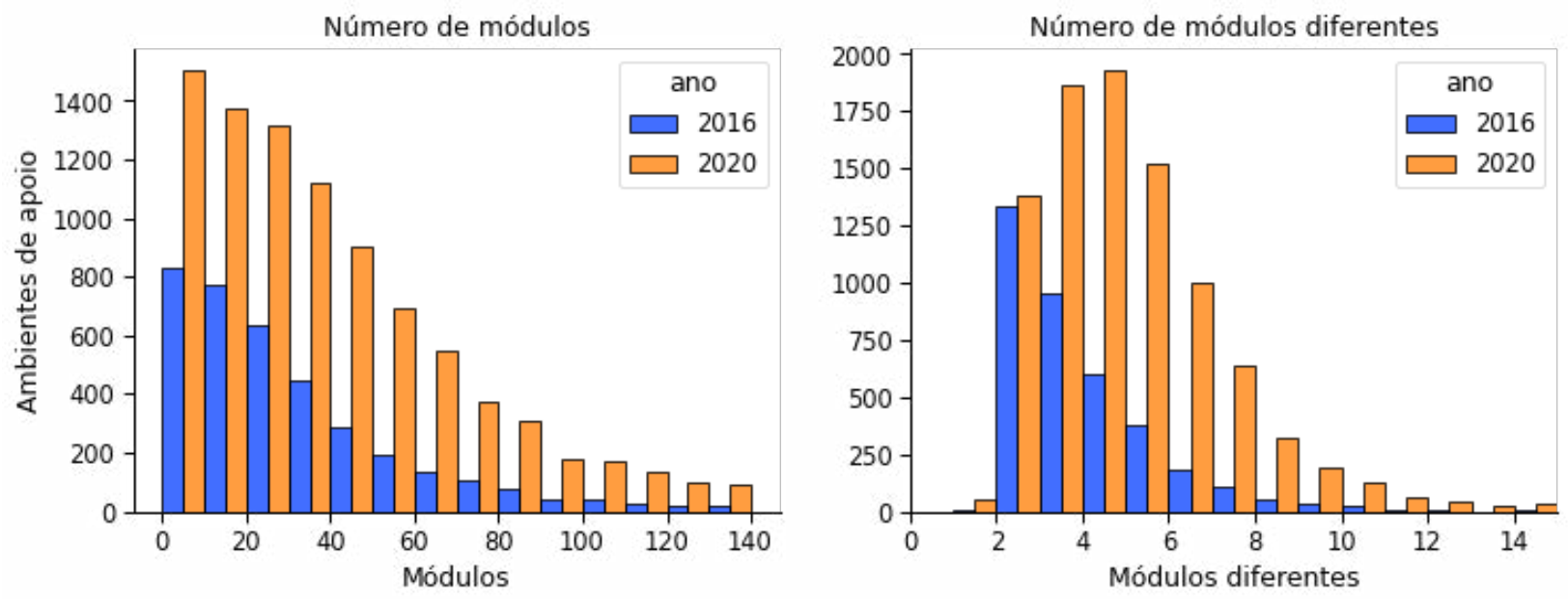

Figura 4: Distribuição de quantidade de módulos (atividades e recursos) usados pelos docentes da USP na plataforma e-Disciplinas. Esquerda: número de módulos. Direita: número de módulos de tipos diferentes.

A estrutura do ambiente e os tipos de módulo escolhidos pelo docente não necessariamente refletem suas intenções e as oportunidades educacionais criadas para os alunos. Existem muito mais métricas que podem fornecer uma melhor compreensão de como os estudantes interagem com os recursos no AVA. Alguns exemplos incluem o número de acessos ou tempo que o aluno fica no AVA. A Tabela 1, por exemplo, mostra alguns indicadores de uso do e-Disciplinas, comparando os anos 2019 e 2020. O nível geral de atividade e a fração dos matriculados que de fato interagem com as atividades propostas aumentaram, como esperado. Há uma grande variação por Unidade o que também era esperado. É importante ressaltar, porém, que não é apropriado tirar conclusões a partir destes indicadores, sem um entendimento mais qualitativo da forma como os ambientes online são usados no contexto de cada unidade. A construção de indicadores que atendam às necessidades de cada ator no ambiente educacional (dirigentes, docentes, estudantes) deve ser objeto de estudo e debate contínuo.

\begin{tabular}{lllllll}
\hline Unidade & \multicolumn{2}{l}{$\begin{array}{l}\text { total de acessos } \\
\text { (por matriculado) }\end{array}$} & \multicolumn{2}{l}{ acessos / atividade } & \multicolumn{2}{l}{ alcance (\%) } \\
\hline & $\mathbf{2 0 1 9}$ & $\mathbf{2 0 2 0}$ & $\mathbf{2 0 1 9}$ & $\mathbf{2 0 2 0}$ & $\mathbf{2 0 1 9}$ & $\mathbf{2 0 2 0}$ \\
\hline FMRP & 463 & 1881 & 4,5 & 9,5 & 58 & 88 \\
\hline FEA & 444 & 1144 & 5,5 & 8,5 & 69 & 77 \\
\hline FD & 183 & 761 & 1,6 & 5,5 & 41 & 57 \\
\hline IF & 741 & 1518 & 4,8 & 9,1 & 43 & 64 \\
\hline
\end{tabular}

Tabela 1: Acessos e alcance com as principais atividades da plataforma e-Disciplinas (fórum, tarefa e questionário). O alcance é a fração dos estudantes matriculados que interagiram pelo menos uma vez com as atividades. Mostramos o valor mediano das atividades disponibilizadas. Foram analisados fóruns, tarefas e questionários com pelo menos 10 acessos e em disciplinas com mais do que 10 estudantes. 


\section{CONCLUSÃO}

Os usuários de AVAs muitas vezes caracterizam-nos como "plataformas" de ensino, dando a impressão instrumentalista de ser uma mera ferramenta neutra que os docentes podem configurar de acordo com suas metodologias pedagógicas. Argumentamos que esta ideia ignora que os AVAs, assim como qualquer tecnologia, têm estrutura própria e interagem com os sistemas sociais em que estão inseridos. Uma maneira interessante de conceitualizar os AVAs nesta perspectiva, é pela noção de tecnologias prescritivas da Ursula Franklin ${ }^{18}$. É a ideia de que determinadas tecnologias incorporam conhecimento institucional sobre como as coisas devem ser feitas, mas também que as tecnologias podem induzir e assegurar compliance.

Acredito que análises críticas frente ao uso de tecnologias educacionais como as descritas acima são necessárias para evitar o risco de precarização e desprofissionalização ${ }^{19}$ do papel dos docentes nas instituições de ensino. Trata-se do risco, se não houver algum tipo de normatização e regramento, de que as tecnologias educacionais sejam usadas para fins de controle gerencial dos docentes e estudantes. Além disso, com a crescente especialização em ensino online, é possível que várias funções como orientação, produção de material, avaliação, normalmente integradas na prática docente, fiquem cada vez mais desmembradas em funções especializadas exercidas por profissionais não docentes, com caráter mais técnico.

Nesta perspectiva, é essencial que instituições de ensino como a USP, primeiro, mantenham autonomia e capacidade técnica de organizar seus próprios ambientes de aprendizagem online, e segundo, que façam isso conforme seus próprios valores político-pedagógicos, fazendo uso consciente e crítico das tecnologias educacionais modernas.

\section{REFERÊNCIAS}

1. Hargittai E. The Digital Reproduction of Inequality. In: Grusky D, organizador. Social Stratification [Internet]. Boulder, CO: Westview Press; 2008 [citado 19 de maio de 2009]. p. 93644. Disponível em: http://webuse.org/p/c11/

2. Rogers EM. Diffusion of innovations. 5th ed. New York: Free Press; 2003. $551 \mathrm{p}$
3. Porter WW, Graham CR, Bodily RG, Sandberg DS. A qualitative analysis of institutional drivers and barriers to blended learning adoption in higher education. Internet High Educ. 2016;28:17-27.

4. Porter WW, Graham CR. Institutional drivers and barriers to faculty adoption of blended learning in higher education. Br J Educ Technol. 2016;47:748-62.

5. Edgerton DL. The shock of the old: technology and global history since 1900. London: Profile Books; 2008. 270 p.

6. Cuban L. Oversold and underused: Computers in the classroom. Cambridge, Massachusetts: Harvard University Press; 2001. 256 p.

7. Langdon Winner. Do Artifacts Have Politics? Daedalus [Internet]. 1980;109. Disponível em: http://www.jstor. org/stable/20024652

8. Kranzberg M. Technology and History: "Kranzberg's Laws". Technol Cult. 1986;27:544-60.

9. Norman DA. The design of everyday things. Revised and expanded edition. New York, New York: Basic Books; 2013. 347 p.

10. Weller M. 25 years of ed tech [Internet]. 2020 [citado 27 de fevereiro de 2020]. Disponível em: https://www. aupress.ca/app/uploads/12029099Z Weller 2020-25 Years of Ed Tech.pdf

11. LARC. COL - Cursos Online [Internet]. COL - Cursos Online. [citado 14 de dezembro de 2020]. Disponível em: https://www.larc.usp.br/col/

12. USP. Tidia-Ae 4.0 [Internet]. [citado 14 de dezembro de 2020]. Disponível em: https://ae4.tidia-ae.usp.br/portal\#

13. Sakai. Sakai Learning Management System [Internet]. Sakai LMS. 2020 [citado 10 de dezembro de 2020]. Disponível em: https://www.sakailms.org

14. Moodle. Moodle - Open-source learning platform [Internet]. [citado 10 de dezembro de 2020]. Disponível em: https://moodle.org/

15. NIED. TelEduc [Internet]. 2017 [citado 10 de dezembro de 2020]. Disponível em: https://www.nied.unicamp. br/projeto/teleduc/

16. Univesp. Univesp - História [Internet]. 2020 [citado 9 de dezembro de 2020]. Disponível em: https://univesp.br/ institucional/historia

17. Tony Bates. Teaching in a Digital Age [Internet]. BC campus; 2015 [citado 15 de março de 2020]. Disponível em: https://doi.library.ubc.ca/10.14288/1.0224023

18. Franklin UM. The real world of technology. Rev. ed. Toronto, Ont. : Berkeley, CA: House of Anansi Press ; Distributed in the United States by Publishers Group West; 2004. 206 p. (CBC Massey lectures series).

19. Chakraborty S. Deskilling of the Teaching Profession. In: Sociology of Education: An A-to-Z Guide [Internet]. 2455 Teller Road, Thousand Oaks California 91320 United States: SAGE Publications, Inc.; 2013 [citado 31 de maio de 2019]. Disponível em: http://sk.sagepub. com/reference/sociology-of-education/n107.xml 
Corresponding Author:

Ewout ter Haar

ewout@usp.br

Editor:

Prof. Dr. Marcelo Riberto

Recebido: 30/04/2021

Aprovado: $13 / 07 / 2021$

(c) (i) Este é um artigo publicado em acesso aberto (Open Access) sob a licença Creative

sem restrições, desde que o trabalho original seja corretamente citado. 